\title{
Esterified Estrogens and Conjugated Equine Estrogens and the Risk of Venous Thrombosis
}

\begin{abstract}
Nicholas L. Smith, PhD
Susan R. Heckbert, MD, PhD

Rozenn N. Lemaitre, PhD

Alex P. Reiner, MD, MPH

Thomas Lumley, PhD

Noel S. Weiss, MD, DrPH

Eric B. Larson, MD, MPH

Frits R. Rosendaal, MD

Bruce M. Psaty, MD, PhD

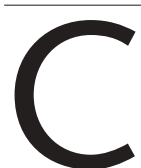

Linical tRIal EVIDENCE FROM the Heart and Estrogen/ progestin Replacement Study (HERS) and the Women's Health Initiative (WHI) indicates that estrogen therapy, with or without progestins, is associated with an increased risk of venous thrombosis (VT) in postmenopausal women. ${ }^{1-3}$ The HERS investigators observed a relative risk of 2.7 (95\% confidence interval $[\mathrm{CI}], 1.4-$ 5.0) for estrogen plus progestin therapy, and the WHI investigators observed a relative risk of 2.1 (95\% CI, 1.6-2.8) and 1.3 (95\% CI, 1.0-1.8) for estrogen with and without concomitant progestin use, respectively. Each of these trials evaluated oral conjugated equine estrogens (CEEs) and medroxyprogesterone acetate.

Various estrogen compounds and their modes of administration are known to differ in estrogen constituents, metabolism, and their affinity for estrogen receptors. ${ }^{4,5}$ Clinical comparison studies of these compounds have focused mainly on mode of delivery, and outcomes have generally been restricted to the relief of menopausal symptoms and the occurrence of vagi-
\end{abstract}

\section{See also p 1573.}

Context Clinical trial evidence indicates that estrogen therapy with or without progestins increases venous thrombotic risk. The findings from these trials, which used oral conjugated equine estrogens, may not be generalizable to other estrogen compounds.

Objective To compare risk of venous thrombosis among esterified estrogen users, conjugated equine estrogen users, and nonusers.

Design, Setting, and Participants This population-based, case-control study was conducted at a large health maintenance organization in Washington State. Cases were perimenopausal and postmenopausal women aged 30 to 89 years who sustained a first venous thrombosis between January 1995 and December 2001 and controls were matched on age, hypertension status, and calendar year.

Main Outcome Measure Risk of first venous thrombosis in relation to current use of esterified or conjugated equine estrogens, with or without concomitant progestin. Current use was defined as use at thrombotic event for cases and a comparable reference date for controls.

Results Five hundred eighty-six incident venous thrombosis cases and 2268 controls were identified. Compared with women not currently using hormones, current users of esterified estrogen had no increase in venous thrombotic risk (odds ratio [OR], $0.92 ; 95 \%$ confidence interval $[\mathrm{Cl}], 0.69-1.22)$. In contrast, women currently taking conjugated equine estrogen had an elevated risk (OR, 1.65; $95 \% \mathrm{Cl}, 1.24-2.19)$. When analyses were restricted to estrogen users, current users of conjugated equine estrogen had a higher risk than current users of esterified estrogen $(\mathrm{OR}, 1.78 ; 95 \% \mathrm{Cl}$, 1.11-2.84). Among conjugated equine estrogen users, increasing daily dose was associated with increased risk (trend $P$ value $=.02$ ). Among all estrogen users, concomitant progestin use was associated with increased risk compared with use of estrogen alone (OR, 1.60; 95\% Cl, 1.13-2.26).

Conclusion Our finding that conjugated equine estrogen but not esterified estrogen was associated with venous thrombotic risk needs to be replicated and may have implications for the choice of hormones in perimenopausal and postmenopausal women.

www.jama.com

nal bleeding. ${ }^{6-8}$ Nearly all comparisons have evaluated the most commonly used estrogens, CEE and micronized estradiol. Esterified estrogens (EEs) have received less attention. All these products, nonetheless, continue to be used to treat menopauserelated vasomotor symptoms in perimenopausal and postmenopausal women.

In October 1999, the Group Health Cooperative (GHC) pharmacies switched the standard postmeno- pausal estrogen therapy from EE to CEE for current and new users of hormone therapy. Formulary switches such as

Author Affiliations: Departments of Epidemiology (Drs Smith, Heckbert, Reiner, Weiss, and Psaty), Medicine (Drs Lemaitre and Psaty), Biostatistics (Dr Lumley), and Health Services (Dr Psaty), University of Washington, Seattle; Center for Health Studies, Group Health Cooperative, Seattle, Wash (Drs Heckbert, Larson, and Psaty); and Leiden University Medical Center, Leiden, the Netherlands (Dr Rosendaal).

Corresponding Author: Nicholas L. Smith, PhD, Cardiovascular Health Research Unit, 1730 Minor Ave, Suite 1360, Seattle, WA 98101 (nlsmith@u.washington .edu). 
these occur in health maintenance organization (HMO) settings when medications are thought to be therapeutically interchangeable. ${ }^{9-11}$ The formulary change occurred during data collection for a case-control study of cardiovascular outcomes that included VT, which presented us with the opportunity to examine the association of oral EE and CEE with VT risk in perimenopausal and postmenopausal women.

\section{METHODS}

\section{Setting and Design}

The setting for this observational study was GHC, a large HMO in western Washington State. Health care delivery and medication prescribing at GHC are based primarily on GHC treatment guidelines. This case-control study of VT was part of a larger, ongoing, population-based, case-control study of VT, myocardial infarction, and stroke and shares with it a single control group. ${ }^{12,13}$ The study was approved by the GHC Human Subjects Review Committee, and informed consent was obtained from individuals who could be contacted and waived by the committee for those who could not be contacted.

\section{Study Population}

Study participants were perimenopausal and postmenopausal female GHC members aged 30 to 89 years. Cases were all GHC members who experienced a first deep VT (DVT) or pulmonary embolism (PE) diagnosed between January 1, 1995, and December 31,2001 , the most recent year of complete and cleaned data in this ongoing study. The date of the VT served as an index date before which information on hormone use and other exposures was ascertained. Controls were a random sample of GHC members who comprised a pool of individuals shared by several case-control studies. The control group was frequency matched by age (within decade), sex, treated hypertension status, and calendar year of identification to myocardial infarction cases, the largest case group. All controls for this analysis met the same inclusion criteria as VT cases and had no history of DVT or PE. For controls, the index date was a randomly chosen date within the calendar year from which they were selected as a control.

Women with VT were identified from inpatient and outpatient care settings. In the inpatient setting, International Classification of Diseases, Ninth Revision codes were abstracted from GHC hospitalization records, which included hospital stays at GHC and nonGHC facilities. In the outpatient setting, GHC pharmacy records were used to identify women who were dispensed a prescription for a lowmolecular-weight heparin for nonhospitalized DVT treatment. Additionally, women were identified from 3 GHC clinics where a pharmacy-based outpatient treatment protocol for DVT was implemented in 1997.

Trained medical record abstractors reviewed the medical records of all potential cases to verify the diagnosis of VT and to determine how the diagnosis was made. Events were classified as study eligible if they were diagnosed by an imaging modality (Doppler or duplex ultrasound, computed tomography, pulmonary angiography, or ventilation-perfusion scan) or by physician judgment in the presence of symptoms or according to treatment strategies. Ninety-two percent of the eligible cases had positive diagnostic imaging test results.

Menopausal status at the index date was defined by the cessation of ovarian function that occurred naturally or through a bilateral oophorectomy for cases and controls and was based on information collected from the GHC medical record. A woman was considered perimenopausal at the onset of menopausal symptoms. If menopausal status was not explicitly stated in the record, women aged 55 years and older were considered postmenopausal.

\section{Main Outcome Measures}

Hormone Use. Use of hormones was determined by using the GHC computerized pharmacy database that con- tains records of all prescriptions filled through GHC since 1977. More than $95 \%$ of GHC members in this age group fill almost all prescriptions through GHC pharmacies. ${ }^{14}$ Pharmacy data contain detailed information that includes GHC member identification number, drug name, date the prescription was filled, medication strength, quantity of medication prescribed, and dosing instructions or the number of days the supply of medication would last.

Oral estrogen was classified into 3 subgroups: (1) CEE, such as Premarin; (2) EE, such as Estratab and Menest; and (3) other estrogens, primarily micronized estradiol, which accounted for less than $1 \%$ of all estrogen prescriptions during the 7 years of the study. The progestin prescribed was almost exclusively medroxyprogesterone acetate and was dispensed as a separate pill from estrogen for virtually all subjects.

A woman was considered a current user of a hormone if she received enough medication with her last prescription to last until her index date according to an assumption of $80 \%$ compliance. An $80 \%$ compliance adjustment was made by increasing the number of days that a prescription would last by $25 \%$. We excluded women for whom there was no record of a GHC pharmacy prescription being filled in the 5 years before the index date $(n=39)$, women using progestin without estrogen at the index date $(n=38)$, and women who were current users of creams or patches and not using estrogen pills $(n=54)$.

Daily oral estrogen dose was calculated from computerized pharmacy data by using pill strength and dosing instructions or number of supply days. For estrogens other than CEE and EE, estrogen dose was based on CEE equivalents. ${ }^{15}$ Recency of therapy initiation for current hormone users was calculated for CEE and EE separately and was defined as the number of days between the index date and the date of the first prescription fill for the drug that was continually used through the index date. Continual use was defined as 
consecutive prescription refills, assuming $80 \%$ compliance, while also allowing for a 90-day gap between run-out dates and refills. For subjects who were switched from EE to CEE, recency of use pertained only to the duration of use of CEE and did not include time accumulated using EE.

Clinical and Demographic Information. Demographic and healthstatus information was obtained by review of the entire GHC ambulatory medical record up to the index date. Medical conditions included treated hypertension, congestive heart failure, a history of stroke, coagulation disorders (lupus anticoagulant; protein C, protein $S$, and antithrombin deficiencies; and polycythemia vera), hysterectomy, previous oral contraceptive use, and recent inpatient surgical procedures. Information was collected on clinical measures that included most recent weight and height. Demographic information included birth date and race, which was based on clinician notes.

Cancer history information was collected from a GHC cancer registry file, which included all cancers except nonmelanoma skin cancers. Previous hospitalization data and fracture data were collected from GHC administrative files that include diagnoses from inpatient and outpatient care delivered at GHC and non-GHC facilities. Surviving subjects were invited to participate in a telephone interview in which information such as race and smoking status is more reliably collected than from a medical record. In the interview, subjects had the choice of 4 race categories or an option to specify a fifth.

Missing values for demographic and clinical characteristics collected from the medical record or telephone interview were imputed with IVEware software. ${ }^{16}$ Missing data were uncommon, and no more than $2 \%$ of the data for any variable was imputed.

\section{Statistical Analyses}

Multivariate logistic regression was used to model the association between current use of estrogen hormones and the risk of VT. Models estimated relative risks

\begin{tabular}{lcc} 
Table 1. Characteristics of Study Participants, Group Health Cooperative, 1995-2001 \\
\hline \multicolumn{1}{c}{ Characteristic } & $\begin{array}{c}\text { Case Patients } \\
\text { ( } \mathbf{n}=\mathbf{5 8 6})\end{array}$ & $\begin{array}{c}\text { Controls } \\
(\mathbf{n}=\mathbf{2 2 6 8})\end{array}$ \\
\hline Age, mean (SD), y & $69.4(11.6)$ & $68.3(9.9)$ \\
\hline White, No. (\%) & $594(96)$ & $2166(92)$ \\
\hline Body mass index, mean (SD)* & $28.7(7.5)$ & $27.8(6.3)$ \\
\hline Chronic congestive heart failure, No. (\%) & $66(11)$ & $91(4)$ \\
\hline History of stroke, No. (\%) & $51(9)$ & $82(4)$ \\
\hline History of cancer within 5 years of index date, No. (\%) & $150(26)$ & $115(5)$ \\
\hline History of hypercoagulable state, No. (\%) & $2(0.3)$ & $2(0.008)$ \\
\hline Hospitalization in the 30 days before index date, No. (\%) & $117(20)$ & $19(0.8)$ \\
\hline $\begin{array}{l}\text { Fracture of pelvis or lower limb in the 30 days } \\
\text { before index date, No. (\%) }\end{array}$ & $15(3)$ & $7(0.3)$ \\
\hline Perimenopausal, No. (\%) & $14(2)$ & $48(2)$ \\
\hline Hysterectomy, No. (\%) & $249(40)$ & $931(39)$ \\
\hline
\end{tabular}

*Body mass index was measured as weight in kilograms divided by the square of height in meters.

with odds ratios (ORs) and produced 95\% CIs. All multivariate models were adjusted for matching variables that included age (continuous and indicator variables by decade), index year (indicator variables by year), and treated hypertension status (absent vs present). We examined multivariate models that included additional adjustments for suspected confounding variables such as race (white vs other), body mass index (weight in kilograms divided by height in meters squared), cancer history (cancer diagnosed within 5 years of index), hysterectomy status, previous oral contraceptive use, prevalent congestive heart failure, history of stroke, smoking status, recent inpatient surgery, hospitalizations that lasted at least 2 nights in the 30 days before the index date, and fracture of the pelvis or lower limb in the 30 days before the index date. Covariates that confounded risk estimates were retained in final multivariate models using SAS statistical software, version 8.2 (SAS Institute Inc, Cary, NC).

Primary analyses compared current CEE and current EE use with nonuse of hormones and current CEE use with current EE use. The latter comparison minimized issues of confounding by hormone-therapy indication or contraindication. Further analyses stratified the use of CEE and EE by concomitant progestin use. Sensitivity analyses of the primary findings were conducted assuming 100\% compliance with hormone therapy instead of $80 \%$, excluding women who had a predisposing VT risk factor (cancer, recent hospitalization, or fracture) and excluding VT events that were not confirmed with an imaging test.

Estrogen dose analyses, adjusted for progestin use, were restricted to current users of CEE and EE. The daily, modal dose of CEE and EE was 0.625 $\mathrm{mg}$. The low dose mean was $0.3 \mathrm{mg}$ for CEE and EE; high dose mean was 1.67 $\mathrm{mg}$ for EE (range, $1.25-2.5 \mathrm{mg}$ ) and 1.16 $\mathrm{mg}$ for CEE (range, 0.9-2.5 mg). On average, $81 \%$ of estrogen users used the modal dose. The modal dose of EE served as the reference group for dose analyses. Analyses for recency of starting were restricted to current users, and subjects were classified as users for less than 1 year, 1 to 5 years, or more than 5 years, with the latter category serving as the reference. Sensitivity analyses additionally restricted subjects to those who started using hormone therapy while enrolled at GHC. This restriction required that, according to GHC pharmacy data, there be at least 6 months of no hormone use before initiation.

\section{RESULTS}

We identified 586 perimenopausal and postmenopausal women who experienced a first VT: 426 with DVT alone (73\%), 68 with DVT and PE (12\%), and 92 with PE (16\%). Thirty-three of the PE events were fatal. Characteristics of the case patients and controls $(\mathrm{n}=$ 2268) are presented in TABLE 1 . Com- 
pared with controls, cases were more likely to have risk factors for VT, including a history of cancer, prevalent heart failure, and a recent hospitalization or major fracture. A similar percentage of cases $(37 \%)$ and controls (37\%) were current users of an oral estrogen with or without concomitant progestin use.

The percentage of controls using any estrogen therapy remained fairly constant during the 7 years of observation
(32\%, 36\%, 39\%, 37\%, 36\%, 38\%, and $39 \%$ for 1995-2001, respectively) and represents the use of hormones in the larger GHC population of postmenopausal women in the age range included in the study. The FigurE presents the use of EE and CEE estrogen types during this period. The GHC formulary switch from EE to CEE in October 1999 resulted in a substantial proportion of women switching estrogen type. Characteristics of the study popu-

Figure. Percentage of Controls Who Were Hormone Users During a Given Index Year by Type of Hormone, Group Health Cooperative, 1995-2001

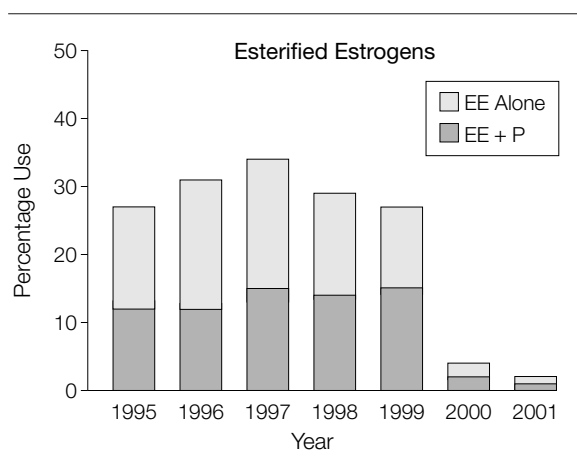

lation according to hormone use are presented in TABLE 2. Compared with nonusers, users were younger, more likely to be white, less likely to have a history of cancer, and more likely to have had a hysterectomy. Among users of hormone therapy, age, hysterectomy status, and daily dose varied by estrogen type.

\section{EE, CEE, and Progestin}

The risk of VT associated with hormone therapy is presented in TABLE 3. Compared with women not currently using hormones, current users of EE had no increase in VT risk (OR, 0.92; 95\% CI, 0.69-1.22), whereas current users of CEE had an elevated risk (OR, 1.65 ; 95\% CI, 1.24-2.19) in analyses adjusted for matching factors and the confounding factors of race and cancer history. Other covariates were considered in the multivariate model but were not included in the final model because they did not confound the hormone-VT association. When adjusted analyses were restricted to hormone users to minimize potential indication bias, current

$E E$ indicates esterified estrogen; $P$, progestin; $C E E$, conjugated equine estrogen.

Table 2. Characteristics of Controls by Hormone Use, Group Health Cooperative, 1995-2001

\begin{tabular}{|c|c|c|c|c|c|c|c|}
\hline \multirow[b]{2}{*}{ Characteristic } & \multirow[b]{2}{*}{$\begin{array}{c}\text { No Hormone } \\
\text { Therapy } \\
(n=1439)\end{array}$} & \multicolumn{6}{|c|}{ Hormone Therapy } \\
\hline & & $\begin{array}{l}\text { All Types } \\
(\mathrm{n}=829)\end{array}$ & $\begin{array}{l}\text { EE Alone } \\
(n=278)\end{array}$ & $\begin{array}{c}\text { EE + } \\
\text { Progestin } \\
(n=237)\end{array}$ & $\begin{array}{c}\text { CEE } \\
\text { Alone } \\
(n=167)\end{array}$ & $\begin{array}{c}\text { CEE + } \\
\text { Progestin } \\
(n=122)\end{array}$ & $\begin{array}{l}\text { Other } \\
(n=25)\end{array}$ \\
\hline Age, mean (SD), y & $70.1(9.1)$ & $65.3(10.3)$ & $66.9(10.1)$ & $62.8(9.9)$ & $67.2(10.2)$ & $64.1(10.2)$ & $65.1(12.2)$ \\
\hline White, No. (\%) & $1390(90)$ & $776(94)$ & $260(94)$ & $222(94)$ & $190(96)$ & $110(90)$ & $24(96)$ \\
\hline Body mass index, mean (SD) & $27.8(6.4)$ & $27.8(6.2)$ & $28.3(6.0)$ & $27.3(6.5)$ & $28.4(6.2)$ & $27.4(5.7)$ & $26.2(5.1)$ \\
\hline Chronic congestive heart failure, No. (\%) & $64(4)$ & $27(3)$ & $14(5)$ & $7(3)$ & $3(2)$ & $3(2)$ & $0(0)$ \\
\hline History of stroke, No. (\%) & $61(4)$ & $21(3)$ & $6(2)$ & $5(2)$ & $6(4)$ & $2(2)$ & $2(8)$ \\
\hline History of cancer within 5 years of index, No. (\%) & $100(7)$ & $15(2)$ & $6(2)$ & $3(1)$ & $3(2)$ & $3(2)$ & $0(0)$ \\
\hline History of hypercoagulable state, No. (\%) & $2(0.1)$ & $0(0)$ & $0(0)$ & $0(0)$ & $0(0)$ & $0(0)$ & $0(0)$ \\
\hline $\begin{array}{l}\text { Hospitalization in the } 30 \text { days } \\
\text { before index date, No. (\%) }\end{array}$ & $14(1)$ & $5(1)$ & $2(1)$ & $0(0)$ & $1(1)$ & $2(2)$ & $0(0)$ \\
\hline $\begin{array}{l}\text { Fracture of pelvis or lower limb in the } 30 \text { days } \\
\text { before index date, No. (\%) }\end{array}$ & $6(0.4)$ & $1(0.1)$ & $0(0)$ & $0(0)$ & $0(0)$ & $1(1)$ & $0(0)$ \\
\hline Perimenopausal, No. (\%) & $32(2)$ & $16(2)$ & $3(1)$ & $9(4)$ & $2(1)$ & $2(2)$ & $0(0)$ \\
\hline Hysterectomy, No. (\%) & $498(32)$ & $433(52)$ & $253(91)$ & $5(2)$ & $156(93)$ & $4(3)$ & $15(60)$ \\
\hline \multicolumn{8}{|l|}{ Recency of starting hormone therapy, No. (\%) } \\
\hline $1-5 y$ & & $433(52)$ & $160(58)$ & $141(59)$ & $78(47)$ & $44(36)$ & $10(40)$ \\
\hline$>5 y$ & & $171(21)$ & $81(29)$ & $42(18)$ & $29(17)$ & $16(13)$ & $3(12)$ \\
\hline $\begin{array}{l}\text { Estrogen daily dose, No. (\%) } \\
\quad<0.625 \mathrm{mg}\end{array}$ & & $87(10)$ & $30(11)$ & $25(11)$ & $15(9)$ & $11(9)$ & $6(24)$ \\
\hline $0.625 \mathrm{mg}$ & & $672(81)$ & $231(83)$ & $206(87)$ & $116(69)$ & $103(84)$ & $16(64)$ \\
\hline$\geq 0.625 \mathrm{mg}$ & & $70(8)$ & $17(6)$ & $6(1)$ & $36(22)$ & $8(7)$ & $3(12)$ \\
\hline
\end{tabular}

Abbreviations: CEE, conjugated equine estrogen; $\mathrm{EE}$, esterified estrogen; other, non-CEE and non-EE estrogens. 
use of CEE was associated with an increase in VT risk compared with current use of EE (OR, 1.78; 95\% CI, 1.112.84). There was little evidence of confounding in hormone-only models (Table 3, models 3 and 4).

Current hormone exposure was further divided to differentiate estrogen therapy opposed and unopposed with progestin (TABLE 4). Compared with women not currently using hormone therapy, current users of EE alone, EE with progestin, and CEE alone had no appreciable increase in VT risk, whereas current users of CEE with progestin had a 2-fold increase in risk (OR, 2.17; 95\% CI, 1.49-3.14) in adjusted analyses. In adjusted analyses restricted to hormone users, current users of CEE alone had a borderline increase in VT risk (OR, 1.74; 95\% CI, 0.96-3.16), and current users of CEE with progestin had nearly a 3-fold increase in risk (OR, 2.94; 95\% CI, 1.60-5.40) compared with current users of EE alone. In analyses restricted to estrogen and progestin users, current use of CEE with progestin was associated with a 2-fold increase in VT risk (OR, 2.02; 95\% CI, 1.05-3.88) compared with current use of EE with progestin.

There were 470 controls and cases who used concomitant progestin among the 1011 users of CEE or EE. The risk of VT associated with the current use of estrogen plus progestin was increased compared with use of estro- gen alone (OR, 1.60; 95\% CI, 1.132.26) in analyses that adjusted for estrogen type, cancer history, race, and the matching variables.

Sensitivity analyses did not meaningfully alter the risk estimates for the association of EE and CEE with VT. When current use was defined assuming $100 \%$ compliance with hormone prescriptions, the OR for VT risk was 0.99 (95\% CI, 0.74-1.33) for EE use and 1.50 (95\% CI, 1.12-2.01) for CEE use compared with nonuse. When controls and cases who had predisposing VT risk factors were excluded, the OR was 1.11 (95\% CI, 0.80-1.56) for EE use and 1.71 (95\% CI, 1.23-2.37) for CEE use compared with nonuse. When VT events not confirmed by imaging were excluded, the OR was 0.99 (95\% CI,
0.74-1.33) for EE use and 1.75 (95\% CI, 1.30-2.35) for CEE use vs nonuse.

\section{Dose and Recency of Hormone Initiation}

Compared with current use of the modal dose of EE, low- and high-dose EE were not associated with an increased or decreased risk of VT in adjusted analyses (TABLE 5). When compared with current use of the modal dose of EE, lowdose CEE was not associated with an increased risk of VT, whereas modal and high-dose CEE were associated with increased VT risk in adjusted analyses. When analyses were restricted to women who used CEE, there was a positive dose-response relationship between CEE dose and VT risk ( $P$ value for MantelHaenszel $\chi^{2}$ for trend $=.02$ ).

Table 3. Risk of Venous Thrombosis Associated With Esterified Estrogen (EE) and Conjugated Equine Estrogen (CEE), Group Health Cooperative, 1995-2001*

\begin{tabular}{|c|c|c|c|}
\hline & & Current Hormon & \\
\hline & None & EE, Any & CEE, Any \\
\hline $\begin{array}{l}\text { Participants, No. } \\
\text { Cases }\end{array}$ & 372 & 86 & 121 \\
\hline Controls & 1439 & 515 & 289 \\
\hline $\begin{array}{c}\text { Model, OR }(95 \% \mathrm{Cl}) \\
\text { All participants } \\
1 \dagger\end{array}$ & Reference & $0.75(0.57-0.98)$ & $1.37(1.05-1.80)$ \\
\hline$\overline{2 \ddagger}$ & Reference & $0.92(0.69-1.22)$ & $1.65(1.24-2.19)$ \\
\hline $\begin{array}{l}\text { Hormone users only } \\
3 \dagger\end{array}$ & NA & Reference & $1.81(1.16-2.84)$ \\
\hline $4 \ddagger$ & NA & Reference & $1.78(1.11-2.84)$ \\
\hline
\end{tabular}

Abbreviations: $\mathrm{Cl}$, confidence interval; $\mathrm{NA}$, not applicable; OR, odds ratio.

*Excludes 7 case and 25 control participants who were current users of non-EE and non-CEE estrogen.

†Adjusted for matching factors.

$\ddagger$ Adjusted for matching factors, race, and cancer history.

Table 4. Risk of Venous Thrombosis Associated With Esterified Estrogen (EE), Conjugated Equine Estrogen (CEE), and Progestin, Group Health Cooperative, 1995-2001*

\begin{tabular}{|c|c|c|c|c|c|}
\hline & & & Current Hormon & & \\
\hline & None & EE Alone & $\mathrm{EE}+$ Progestin & CEE Alone & CEE + Progestin \\
\hline $\begin{array}{l}\text { Participants, No. } \\
\text { Cases }\end{array}$ & 372 & 39 & 47 & 57 & 64 \\
\hline Controls & 1439 & 278 & 237 & 167 & 122 \\
\hline $\begin{array}{l}\text { Model, OR (95\% Cl) } \\
\text { All participants }\end{array}$ & & & & & \\
\hline $1 \dagger$ & Reference & $0.66(0.45-0.95)$ & $0.85(0.60-1.21)$ & $1.16(0.82-1.64)$ & $1.67(1.17-2.39)$ \\
\hline $2 \ddagger$ & Reference & $0.78(0.53-1.15)$ & $1.08(0.75-1.56)$ & $1.31(0.91-1.88)$ & $2.17(1.49-3.14)$ \\
\hline $\begin{array}{l}\text { Hormone users only } \\
3 \dagger\end{array}$ & NA & Reference & $1.38(0.85-2.22)$ & $1.81(1.03-3.18)$ & $2.66(1.49-4.74)$ \\
\hline $4 \ddagger$ & NA & Reference & $1.50(0.91-2.47)$ & $1.74(0.96-3.16)$ & $2.94(1.60-5.40)$ \\
\hline
\end{tabular}

Abbreviations: $\mathrm{Cl}$, confidence interval; NA, not applicable; OR, odds ratio.

*Excludes 7 case and 25 control participants who were current users of non-EE and non-CEE estrogen.

†Adjusted for matching factors.

$\ddagger$ Adjusted for matching factors, race, and cancer history. 
Table 5. Risk of Venous Thrombosis Associated With Hormone Replacement Therapy According to Daily Dose, Group Health Cooperative, 1995-2001*

\begin{tabular}{|c|c|c|c|}
\hline Dose & Case Patients & Controls & Adjusted OR (95\% Cl)† \\
\hline \multicolumn{4}{|l|}{$\overline{\mathrm{EE}}$} \\
\hline Low & 12 & 55 & $1.32(0.63-2.77)$ \\
\hline Modal & 71 & 437 & 1.00 \\
\hline High & 3 & 23 & $1.18(0.33-4.24)$ \\
\hline \multicolumn{4}{|l|}{$\overline{\mathrm{CEE}}$} \\
\hline Low & 8 & 26 & $1.21(0.46-3.17)$ \\
\hline Modal & 91 & 219 & $1.68(1.01-2.78)$ \\
\hline High & 22 & 44 & $3.80(1.90-7.61)$ \\
\hline
\end{tabular}

Compared with controls and cases using EE for more than 5 years, starting EE in the year before the index date (OR, 1.26 ; $95 \% \mathrm{CI}, 0.56-2.83$ ) or 1 to 5 years before the index date (OR, 1.08; $95 \%$ CI, 0.54-2.15) was not associated with an increased risk in adjusted analyses. Compared with control and case using CEE more than 5 years, starting $\mathrm{CEE}$ in the year before the index date (OR, $0.89 ; 95 \%$ CI, $0.40-1.97$ ) or 1 to 5 years before the index date (OR, 1.54; $95 \%$ CI, 0.72-3.28) was also not associated with an increased risk. Odds ratios did not differ appreciably in sensitivity analyses.

\section{COMMENT}

In this observational study, compared with nonuse of hormone therapy, CEE use but not EE use was associated with an increased risk of VT in adjusted analyses. Compared with EE use, CEE use was associated with an increase in risk. Among CEE users, there was evidence of a dose-response relationship with VT risk. No association was detected between recency of starting either CEE or EE therapy and VT risk. Use of estrogen plus progestin was associated with an increase in risk of VT compared with use of estrogen alone.

Our results are in agreement with and expand on previous experimental and observational findings of VT risk associated with hormone use in postmenopausal women. For CEE plus progestin, the HERS relative risk of 2.7 (95\% CI, 1.4-5.0) and the WHI relative risk of 2.1 (95\% CI, 1.6-2.8) are similar to the OR of 2.17 (95\% CI, 1.49-3.14) re- ported in this study for CEE plus progestin use compared with nonuse of hormones. ${ }^{1,2}$ For CEE without progestin, the WHI relative risk of 1.3 (95\% CI, 1.01.8) is again similar to our findings of an OR of 1.31 (95\% CI, 0.91-1.88). ${ }^{3}$ For EE, no clinical trial or observational data are available for VT risk.

Comparison of hazard ratios (2.1 vs 1.3) from the CEE plus medroxyprogesterone acetate and the CEE-alone arms of WHI would suggest that this progestin compound is associated with a $62 \%$ increase in risk. We observed a $60 \%$ increase in risk (OR, 1.60; 95\% CI, 1.132.26). Unlike findings from the CEE plus progestin clinical trials that showed larger risks in recent hormone starters compared with longer-term users, ${ }^{1,2}$ we did not find that recent starting-particularly use in the first year-was associated with an increased risk of VT.

Several issues should be considered when this study's findings are evaluated. First, the use of hormone therapy was not randomly assigned. Women and their physicians chose whether to use hormones according to clinical indication, which can induce confounding. The type of estrogen received, however, was dictated primarily by changes over time in the GHC formulary and not by patient or physician choice: women treated before October 1999 primarily received EE, whereas women treated after this date received CEE. This unanticipated estrogen switch was not included as a primary aim of the original research. Use of hormone therapy was prospectively collected in the GHC pharmacy database and not subject to recall or infor- mation bias. The design of this study is population-based so that controls are representative of the population from which the cases arose. Findings are generalizable only to similar populations, primarily white perimenopausal and postmenopausal women without a previous VT.

Conjugated equine estrogens contain 10 known biologically active estrogen compounds, as well as others that have yet to be described, which has prevented the manufacture of a generic version. ${ }^{4,17}$ The primary compounds are estrone sulfate, constituting approximately $53 \%$ of the estrogens, and equilin sulfate, constituting about $25 \%$ of the product. ${ }^{5,17}$ Esterified estrogens contain approximately $80 \%$ estrone sulfate and approximately $11 \%$ equilin sulfate. ${ }^{5}$ In vivo, there is active conversion of estrogen components so that plasma concentration ratios of these hormones tend to be similar across estrogen products other than transdermal estrogen preparations, which bypass liver metabolism and produce higher estradiol levels. ${ }^{5,18} \mathrm{Com}$ parative pharmacologic data for $\mathrm{CEE}$ and EE are limited. ${ }^{18}$

In both experimental and observational settings, prescription estrogens, primarily micronized estradiol and CEE, are associated with changes in the plasma levels of several proteins or markers of the coagulation, anticoagulation, and fibrinolysis pathways that create a prothrombotic environment. These compounds increase plasma levels of tissue activatable fibrinolysis inhibitor antigen $^{19,20}$; protein $C^{21}$; factors VII, IX, and $\mathrm{X}^{22-25}$; and D-dimer ${ }^{20,26}$ and decrease the levels of protein $S,{ }^{27,28}$ soluble thrombomodulin, ${ }^{29}$ antithrombin,,$^{21,27,28}$ and tissue plasminogen activators. ${ }^{24,28} \mathrm{Few}$ studies have addressed EE's effects on clotting factors, although its role in stress response, bone density, lipid levels, and endometrial hyperplasia has been published with data from placebocontrolled trials. ${ }^{30,31}$ Clinical comparison studies of EE and CEE are limited to a single crossover trial that reported significantly better short-term cognitive function and depression scores during EE use compared with CEE use in menopausal women. ${ }^{32}$ 
Data from this observational study provide a comparison of oral estrogen products in relation to the risk of first VT. Findings suggest that compared with nonuse of hormone therapy, oral CEE therapy increases the risk of VT dose-dependently, EE does not influence VT risk, and the use of any estrogen in combination with medroxyprogesterone acetate increases risk as well.

Our findings for VT risk need to be replicated, and the association of EE and CEE with other adverse outcomes of es- trogen use should be investigated. If replicated, these findings for VT may have implications for the choice of hormone in treating menopause-related vasomotor symptoms in perimenopausal and postmenopausal women.

Author Contributions: Dr Smith had full access to all of the data in the study and takes responsibility for the integrity of the data and the accuracy of the data analysis.

Study concept and design: Smith, Heckbert, Reiner, Rosendaal, Psaty.

Acquisition of data: Smith, Heckbert, Psaty. Analysis and interpretation of data: Smith, Heckbert, Lemaitre, Reiner, Lumley, Weiss, Larson, Rosendaal, Psaty.
Drafting of the manuscript: Smith.

Critical revision of the manuscript for important intellectual content: Heckbert, Lemaitre, Reiner, Lumley, Weiss, Larson, Rosendaal, Psaty.

Statistical analysis: Smith, Heckbert, Lemaitre, Lumley. Obtained funding: Smith, Heckbert, Psaty.

Administrative, technical, or material support: Smith, Heckbert, Larson, Rosendaal, Psaty.

Study supervision: Smith, Heckbert, Weiss, Psaty. Funding/Support: The research reported in this article was supported by National Heart, Lung, and Blood Institute grants HL73410 (Dr Smith), HL60739 (Dr Psaty), HL68639 (Dr Psaty), HL43201 (Dr Psaty), HL74745 (Dr Psaty), HL68986 (Dr Heckbert), and National Institute on Aging grant AG09556 (Dr Psaty).

Role of the Sponsor: The funding organizations had no role in the conduct and design of the study; in the collection, analysis, and interpretation of the data; or in the preparation, review, or approval of the manuscript.

\section{REFERENCES}

1. Grady D, Wenger NK, Herrington D, et al. Postmenopausal hormone therapy increases risk for venous thromboembolic disease: the Heart and Estrogen/ progestin Replacement Study. Ann Intern Med. 2000; 132:689-696.

2. Writing Group for the Women's Health Initiative Investigators. Risks and benefits of estrogen plus progestin in healthy postmenopausal women: principal results from the Women's Health Initiative randomized controlled trial. JAMA. 2002;288: 321-333.

3. Anderson $G L$, Limacher $M$, Assaf AR, et al. Effects of conjugated equine estrogen in postmenopausal women with hysterectomy: the Women's Health Initiative randomized controlled trial. JAMA. 2004;291: 1701-1712.

4. Ansbacher R. The pharmacokinetics and efficacy of different estrogens are not equivalent. $\mathrm{Am} J \mathrm{Ob}$ stet Gynecol. 2001;184:255-263.

5. O'Connell MB. Pharmacokinetic and pharmacologic variation between different estrogen products. J Clin Pharmacol. 1995;35(9 suppl):18S-24S.

6. Nelson HD. Commonly used types of postmenopausal estrogen for treatment of hot flashes: scientific review. JAMA. 2004;291:1610-1620.

7. Good WR, John VA, Ramirez M, Higgins JE. Comparison of Alora estradiol matrix transdermal delivery system with oral conjugated equine estrogen therapy in relieving menopausal symptoms: Alora Study Group. Climacteric. 1999;2:29-36.

8. von Holst T, Lang E, Winkler U, Keil D. Bleeding patterns in peri- and postmenopausal women taking a continuous combined regimen of estradiol with norethisterone acetate or a conventional sequential regimen of conjugated equine estrogens with medrogestone. Maturitas. 2002;43:265-275.

9. Kaplan RC, Psaty BM, Kriesel D, et al. Replacing short-acting nifedipine with alternative medications at a large health maintenance organization. Am J Hypertens. 1998;11:471-477.

10. Andrade SE, Gurwitz JH, Cernieux J, Fish LS. Evaluation of a formulary switch from conjugated to esterified estrogens in a managed care setting. Med Care. 2000:38:970-975.

11. Gardner J, Scholes D, Baluch W, Krauss R. Acceptability of a substitution of estrogen replacement therapy to women enrolled in a health main-

tenance organization. J Womens Health. 1998; 7:1027-1031

12. Psaty BM, Heckbert SR, Atkins D, et al. The risk of myocardial infarction associated with the combined use of estrogens and progestins in postmenopausal women. Arch Intern Med. 1994;154: 1333-1339.

13. Psaty BM, Heckbert SR, Koepsell TD, et al. The risk of myocardial infarction associated with antihypertensive drug therapies. JAMA. 1995;274:620-625. 14. Heckbert SR, Weiss NS, Koepsell TD, et al. Duration of estrogen replacement therapy in relation to the risk of incident myocardial infarction in postmenopausal women. Arch Intern Med. 1997;157: 1330-1336.

15. Lobo RA. Clinical review 27: effects of hormonal replacement on lipids and lipoproteins in postmenopausal women. J Clin Endocrinol Metab. 1991;73:925930.

16. Raghunathan TE, Solenberger PW, van Hoewyk J. IVEware: Imputation and Variance Estimation Software. Ann Arbor: Institute for Social Research, University of Michigan; 1998

17. Bhavnani BR. Pharmacokinetics and pharmacodynamics of conjugated equine estrogens: chemistry and metabolism. Proc Soc Exp Biol Med. 1998;217:616.

18. Jurgens RW Jr, Downey LJ, Abernethy WD, et al. A comparison of circulating hormone levels in postmenopausal women receiving hormone replacement therapy. Am J Obstet Gynecol. 1992; 167:459-460.

19. van Tilburg NH, Rosendaal FR, Bertina RM. Thrombin activatable fibrinolysis inhibitor and the risk for deep vein thrombosis. Blood. 2000;95:2855-2859

20. Meijers JC, Middeldorp S, Tekelenburg W, et al. ncreased fibrinolytic activity during use of oral contraceptives is counteracted by an enhanced factor XIindependent down regulation of fibrinolysis. Thromb Haemost. 2000;84:9-14.

21. Cushman M, Psaty BM, Meilahn EN, Dobs AS, Kuller LH. Post-menopausal hormone therapy and concentrations of protein $\mathrm{C}$ and antithrombin in elderly women. Br J Haematol. 2001:114:162-168.

22. Di Bitondo R, Hall AJ, Peake IR, lacoviello L, Winship PR. Oestrogenic repression of human coagulation factor VII expression mediated through an oes- trogen response element sequence motif in the promoter region. Hum Mol Genet. 2002;11:723-731. 23. Nozaki $M$, Ogata $R$, Koera $K$, et al. Changes in coagulation factors and fibrinolytic components of postmenopausal women receiving continuous hormone replacement therapy. Climacteric. 1999;2:124-130. 24. Lowe GD, Upton MN, Rumley $A$, et al. Different effects of oral and transdermal hormone replacement therapies on factor IX, APC resistance, t-PA, PAI and C-reactive protein: a cross-sectional population survey. Thromb Haemost. 2001;86:550556.

25. Middeldorp S, Meijers JC, van den Ende AE, et al. Effects on coagulation of levonorgestrel- and desogestrel-containing low dose oral contraceptives: a cross-over study. Thromb Haemost. 2000;84:4-8.

26. Teede HJ, McGrath BP, Smolich JJ, et al. Postmenopausal hormone replacement therapy increases coagulation activity and fibrinolysis. Arterioscler Thromb Vasc Biol. 2000;20:1404-1409.

27. Koh KK, Horne MK III, Cannon RO III. Effects of hormone replacement therapy on coagulation, fibrinolysis, and thrombosis risk in postmenopausal women. Thromb Haemost. 1999;82:626-633.

28. Gottsater A, Rendell M, Hulthen UL, Berntorp E, Mattiasson I. Hormone replacement therapy in healthy postmenopausal women: a randomized, placebo-controlled study of effects on coagulation and fibrinolytic factors. J Intern Med. 2001;249: 237-246.

29. Van Baal WM, Emeis JJ, Kenemans $P$, et al. Short-term hormone replacement therapy: reduced plasma levels of soluble adhesion molecules. Eur J Clin Invest. 1999;29:913-921.

30. Meyer WR, Costello N, Straneva P, et al. Effect of low-dose estrogen on hemodynamic response to stress. Fertil Steril. 2001;75:394-399.

31. Genant HK, Lucas J, Weiss S, et al. Low-dose esterified estrogen therapy: effects on bone, plasma estradiol concentrations, endometrium, and lipid levels. Arch Intern Med. 1997;157:2609-2615.

32. Friebely JS, Shifren JL, Schiff I, Regestein QR. Preliminary observations on differing psychological effects of conjugated and esterified estrogen treatments. J Womens Health Gend Based Med. 2001;10:181-187. 